\title{
A implementação do Programa Nacional de Alimentação Escolar (PNAE) em municípios do norte do Rio Grande do Sul
}

\author{
La implementación del Programa Nacional de Alimentación Escolar (PNAE) en \\ municipios del norte del Rio Grande do Sul \\ The implementation of the National School Food Program (PNAE) in \\ municipalities in the north of Rio Grande do Sul
}

ELITANA ANTONIOLLI

https://orcid.org/0000-0003-0005-2399 Universidade Federal da Fronteira Sul Programa de Mestrado em Educação Chapecó, SC, Brasil

MARIA SILVIA CRISTOFOLI https://orcid.org/0000-0003-3959-1699 Universidade Federal da Fronteira Sul Programa de Mestrado em Educação Chapecó, SC, Brasil

\begin{abstract}
Resumo: Este artigo versa sobre o Programa Nacional de Alimentação Escolar e se insere no contexto da análise de implementação de políticas públicas educacionais. Apresenta como objetivo principal analisar o processo de implementação do PNAE em municípios situados no norte do estado do Rio Grande do Sul (RS). Estrutura-se na pesquisa documental e bibliográfica acerca da temática, empregando as técnicas de análise documental e entrevistas semiestruturadas. Os resultados demonstram que a implementação do PNAE depende de três pilares básicos: recursos financeiros, agentes da política e sistema normativo que rege o programa.
\end{abstract}

Palavras-chave: PNAE; Alimentação Escolar; Implementação de Políticas Públicas.

\begin{abstract}
This article deals with the National School Meals Program and is part of the analysis of the implementation of public educational policies. Its main objective is to analyze the implementation process of PNAE in municipalities located in the north of the state of Rio Grande do Sul (RS). It is structured in documentary and bibliographical research on the subject, using the techniques of document analysis and semi-structured interviews. The results demonstrate that the implementation of the PNAE depends on three basic pillars: financial resources, agents of the policy, and normative system that governs the program.
\end{abstract}

Keywords: PNAE; School Feeding; Implementation of Public Policies. 
Resumen: Este articulo trata del Programa Nacional de Alimentación Escolar y se inserta en el contexto del análisis de la aplicación de la política pública educativa. Su principal objetivo es analizar el proceso de implementación del PNAE en los municipios ubicados en el norte del estado de Rio Grande do Sul (RS). Se estructura en una investigación documental y bibliográfica sobre el tema, utilizando las técnicas de análisis documental y entrevistas semiestructuradas. Los resultados demuestran que la implementación del PNAE depende de tres pilares básicos: recursos financieros, agentes de la política y sistema regulador que rige el programa.

Palabras clave: PNAE; Alimentación Escolar; Implementación de Políticas Públicas.

\section{INTRODUÇÃO}

A alimentação escolar é um direito assegurado constitucionalmente a todos os estudantes matriculados na rede pública de educação básica do país e que vem se consolidando por meio do Programa Nacional de Alimentação Escolar (PNAE).

O PNAE corresponde a maior e mais longeva política pública em execução no Brasil, cujas ações são reconhecidas mundialmente. Conhecido popularmente como Merenda Escolar, seu projeto inicial data da década de 50 e ao longo de sua trajetória passou por diversas transformações com importantes avanços técnicos e operacionais que culminaram com a atual versão da política.

Atualmente o programa está presente no cotidiano das escolas públicas brasileiras, proporcionando a milhares de estudantes o acesso à alimentação saudável e contribuindo para a sua permanência no ambiente escolar. Representa uma das mais expressivas políticas educacionais no que tange ao volume de recursos financeiros e sua abrangência em relação ao número de alunos beneficiados. Segundo os dados mais recentes disponibilizados no site do Fundo Nacional de Desenvolvimento da Educação (FNDE) ${ }^{1}$ na página destinada ao PNAE, no ano de 2015, foram atendidos pelo programa 41,5 milhões de estudantes e repassados 3,759 bilhões de reais em recursos financeiros a estados, municípios e escolas federais (BRASIL, 2020).

Embora se constitua em uma política de âmbito federal, de caráter suplementar, sua execução ocorre em regime de colaboração com os demais entes federados (estados, municípios e DF). Assim, o governo federal, por intermédio do FNDE, presta assistência técnica e financeiras às entidades executoras $(\mathrm{EEx})^{2}$,

1 O Fundo Nacional de Desenvolvimento da Educação (FNDE) é uma autarquia do Ministério da Educação (MEC), responsável por gerir os programas suplementares do governo federal em âmbito nacional, prestando assistência financeira e técnica às entidades executoras (BRASIL, 2020).

2 As entidades executoras (EEx) são representadas pelas secretarias de educação dos estados, municípios, Distrito Federal e escolas federais, responsáveis pelo desenvolvimento de todas as condições para que o PNAE seja executado em conformidade com o que determina a legislação federal do programa (BRASIL, 2020). 
que por sua vez, são responsáveis por proporcionar as condições necessárias em âmbito local para que o PNAE seja executado em conformidade com o que rege a legislação do programa (BRASIL, 2020).

Apesar de existir um aparato normativo que norteia as ações do programa, quando a política é implementada nos municípios brasileiros ela adota características locais e regionais na qual está inserida podendo apresentar diferentes desdobramentos. Diante disso, o objetivo principal deste artigo foi analisar o processo de implementação do PNAE em municípios situados na região norte do estado do Rio Grande do Sul (RS), procurando identificar os desafios e potencialidades das instituições na implementação do PNAE e contribuir para o aperfeiçoamento das ações desenvolvidas no programa em âmbito local e nacional.

É oportuno destacar que este estudo foi fruto da dissertação intitulada "Programa Nacional de Alimentação Escolar (PNAE): Uma Análise da Implementação em Municípios do Rio Grande do Sul (RS)", desenvolvida junto ao Programa de Pós-Graduação, Stricto Sensu, da Universidade Federal da Fronteira Sul (UFFS), Campus Chapecó/SC, Curso de Mestrado em Educação, vinculada à linha de Pesquisa "Políticas Educacionais" e ao Grupo de Pesquisa "Políticas Públicas, Democracia e Estudos Urbanos".

\section{A EMERGÊNCIA DO DIREITO À ALIMENTAÇÃO ESCOLAR}

Em que pese a alimentação e a educação sejam direitos fundamentais reconhecidos mundialmente, sua existência está atrelada à promulgação da Declaração Universal do Direitos Humanos (DUDH) de 1948, que legitimou em seus artigos XXV e XXVI o direito à alimentação e à educação, respectivamente.

A DUDH representa um marco na trajetória dos direitos humanos, inspirando a construção de outros documentos com princípios e finalidades semelhantes na busca pela proteção e efetivação dos direitos fundamentais aos cidadãos.

Atualmente existem outros dispositivos nacionais e internacionais que asseguram legalmente o acesso dos indivíduos à alimentação e à educação, como o Pacto Internacional sobre Direitos Econômicos, Sociais e Culturais (PIDESC) de 1966, que institui em seu artigo 11 o direito à alimentação e no artigo 13 o direito à educação. Também podemos destacar a Declaração Mundial sobre Educação para Todos da UNESCO (1990) e os 07 Compromissos da Cúpula Mundial da Alimentação (1996). 
Em âmbito nacional, a legislação brasileira por meio da Constituição Federal de 1988 e da Lei de Diretrizes e Bases da Educação Nacional de 1996, reconhece e assegura a alimentação e a educação como direitos sociais. Entretanto, é importante ressaltar que o direito à alimentação passou a compor o artigo $6^{\circ} \mathrm{da}$ CF de 1988 apenas em 2010 por meio da Emenda Constitucional no 64. Ou seja, embora a alimentação seja um direito fundamental amplamente reconhecido é recente a sua inclusão na legislação brasileira.

Diante disso, é oportuno evidenciar o pensamento de Bobbio (1992) ao afirmar que a existência de um direito implica necessariamente a existência de um aparato normativo, composto por um conjunto de normas que guiem a própria ação. $\mathrm{O}$ autor ainda destaca que "a figura do direito tem como correlato a figura da obrigação” (BOBBIO, 1992, p. 79-80). Em outras palavras, o reconhecimento de um direito requer ações que possam positivá-lo socialmente, exigindo de seus provedores a sua efetivação.

Neste cenário, emerge o direito à alimentação escolar legitimado no artigo $208^{\circ} \mathrm{da}$ CF, inciso VII, e no artigo $4^{\circ} \mathrm{da}$ LDB, inciso VIII, ao estabelecerem "O atendimento ao educando, em todas as etapas da educação básica, por meio de programa suplementares de material didático-escolar, transporte, alimentação e assistência à saúde (BRASIL, 1988; LDB, 1996) (Grifos da autora).

No Brasil, o direito à alimentação escolar é efetivado por meio de políticas públicas, neste caso o Programa Nacional de Nacional de Alimentação Escolar (PNAE). Atualmente o PNAE é regido pela Lei Federal 11.947 de 2009 e pela Resolução CD/FNDE n 26 de 2013, que regulamentam e norteiam as ações do programa.

A seguir, introduzimos o conceito de políticas públicas e demais temáticas que emergem deste assunto.

\section{A IMPLEMENTAÇÃO DE POLÍTICAS PÚBLICAS}

De acordo com Souza (2006, p.26), política pública é “o campo do conhecimento que busca, ao mesmo tempo, 'colocar o governo em ação' e/ ou analisar essa ação e, quando necessário propor mudanças no rumo ou curso dessas ações". Já Hofling (2001, p. 31) define que "as políticas públicas podem ser definidas como o Estado implantando um projeto do governo, através de programas, de ações voltadas para setores específicos da sociedade, caracterizando o 'Estado em ação”'.

Embora existam diversos significados e conceitos para o termo política pública, é importante enfatizar que as políticas públicas caracterizam as ações do Estado em relação à sociedade a fim de garantir o bem-estar social dos cidadãos. 
Ou seja, expressam as propostas e estratégias dos governantes por meio de projetos e/ou programas sociais com o objetivo de impactar positivamente a realidade à qual se destinam.

Assim, a construção de uma política pública está associada a um processo de planejamento e estruturação que alguns autores denominam de fases da política, a saber: agenda, formulação, implementação e avaliação (PEREZ, 2010; LIMA e D’ASCENZI, 2013). Embora essas etapas estejam conectadas é possível analisar cada fase independentemente, conforme as características do estudo. Assim, a fase que nos interessa aqui é a da implementação.

Para alguns autores, a implementação se refere ao processo iniciado com o estabelecimento da política até o seu impacto (PEREZ, 2010). Já para outros, a implementação está relacionada com execução de atividades, com o intuito de atingir as metas previstas no processo de formulação das políticas, ou seja, a implementação é uma consequência do processo que lhe deu origem (LIMA e D’ASCENZI, 2013).

Cabe ressaltar que, muitas vezes, a fase de implementação de políticas públicas se configura como um campo de disputas e conflitos, devido às divergências de interesses, ideologias e concepções entre agentes formuladores e implementadores. Neste sentindo, Lima e D’Ascenzi (2013) destacam que grande parte dos desafios da implementação de políticas públicas está na interação da política com as organizações executoras.

Diante disso, alguns autores sugerem que existem fatores essenciais na implementação das políticas públicas, entre eles: 1) o desenho, as características e a estrutura do plano: é importante que os objetivos sejam claros para que os agentes implementadores compreendam a política e o que se espera deles; 2) os arranjos institucionais: no que se refere à estrutura e a dinâmicas organizacionais, disponibilidade de recursos, principalmente o financeiro; 3) os atores implementadores: a divergência de ideias, valores e concepções, além de disputas e conflitos ideológicos-partidários-culturais que podem influenciar na implementação das políticas e/ou programas públicos (FREY, 2000; PEREZ, 2010; LIMA e D'ASCENZI, 2013).

Para além desses fatores, podemos citar também o cenário político, econômico e social, no qual a política ou programa público será implementado e, as mudanças decorrentes da trajetória da própria política. Ou seja, existe uma infinidade de variáveis que podem influenciar na implementação de uma política pública, independente da gestão ou esfera administrativa em que ela seja executada. 
Neste sentindo, Hofling (2001, p. 35) sinaliza que "as ações empreendidas pelo Estado não se implementam automaticamente, têm movimento, têm contradições e podem gerar resultados diferentes dos esperados". Frey (2000, p. 228) corrobora com a autora ao afirmar que "[...] os resultados e impactos reais de certas políticas não correspondem aos impactos projetados na fase da sua formulação". Nesta perspectiva, o PNAE como programa do governo federal, pode apresentar alguns obstáculos e/ou limitações na sua efetivação como política pública em âmbito municipal.

Diante disso, Perez (2010) destaca que estudos sobre a implementação de políticas públicas visam contribuir para: 1) corrigir o curso das ações, fornecendo subsídios aos implementadores durante o curso da política; 2) ampliar a efetividade do processo de decisão dos programas públicos; 3) ampliar a accountability dos programas; 4) ampliar a integração dos corpos administrativo, político e comunidade, fundamentais para a mudança do desempenho educacional.

Há ainda autores que defendem a abordagem do ciclo que políticas utilizam como estratégia para análise de programas e políticas educacionais brasileiras (BALL e BOWE, 1992; MAINARDES, 2006). Segundo Mainardes (2006, p. 48) "essa abordagem permite a análise crítica da trajetória de programas e políticas educacionais desde sua formulação inicial até a sua implementação no contexto da prática e seus efeitos". O autor ainda afirma que:

[...] Essa abordagem destaca a natureza complexa e controversa da política educacional, enfatiza os processos micropolíticos e a ação dos profissionais que lidam com as políticas no nível local e ainda a necessidade de se articularem os processos macro e micro na análise de políticas educacionais (MAINARDES, 2006, p. 49).

Neste sentido Ball e Bowe (1992) caracterizam o processo político como um ciclo contínuo constituído por facetas ou arenas políticas, a saber: a política proposta, a política de fato e a política em uso. Os autores ainda definem que esse ciclo também é constituído por contextos: contexto de influência, contexto da produção de texto, contexto da prática, contexto dos resultados (efeitos) e o contexto da estratégia política.

Aqui, nos interessa, o contexto da prática e o contexto dos resultados ou efeitos. De acordo com Ball e Bowe (1992), no contexto da prática, a política está sujeita à interpretação e recriação dos profissionais que exercem um papel ativo na implementação de políticas educacionais, assim seus valores, crenças, experiências e propósitos podem representar transformações significativas na 
política original. Diante disso, os autores argumentam que as políticas não são simplesmente implementadas, mas estão sujeitas à interpretação dos profissionais que atuam no contexto da prática, recriando a política.

Já o contexto dos resultados e efeitos se preocupa com questões de justiça, igualdade e liberdade individual. Para Mainardes (2006, p. 54):

[...] a ideia que as políticas têm efeitos, em vez de simplesmente resultados, é considerada mais apropriada. Nesse contexto, as políticas deveriam ser analisadas em termos do seu impacto e das interações com desigualdades existentes (MAINRADES, 2006, p. 54).

O autor ainda destaca que o contexto dos resultados e efeitos traz reflexões profundas sobre questões conjunturais e sobre as desigualdades sociais que são criadas ou reproduzidas pela política ou pelo programa (MAINARDES, 2006).

Diante do exposto, pode-se afirmar que a abordagem do ciclo de políticas também representa um importante método para análise crítica da trajetória de políticas e programas educacionais, pois considera as várias fases do processo político e a necessidade de articulação entre os seus estágios macro e micro. Além disso, chama a atenção para o impacto que uma mesma política produz nos diferentes cenários sociais, enfatizando que as políticas são produtos de contínuas relações, reproduzidas em variados contextos que podem ter implicações diferentes no processo de implementação de políticas públicas.

$\mathrm{Na}$ sequência, vamos abordar uma das maiores e mais longevas políticas públicas educacionais do país, o Programa Nacional de Alimentação Escolar (PNAE).

\section{O PROGRAMA NACIONAL DE ALIMENTAÇÃO ESCOLAR: CARACTERÍSTICAS E OPERACIONALIZAÇÃO}

O PNAE representa uma das maiores políticas públicas em curso no país. Instituído pelo Decreto no 37.106 de 31 de março de 1955 que criou a Campanha da Merenda Escolar (CME), neste ano de 2021, o programa completa 66 anos de existência. Seu projeto inicial tinha como objetivo prestar assistência aos estudantes vulneráveis à desnutrição, atualmente o PNAE corresponde à efetivação de um direto, o direito à alimentação escolar.

Aliado a isso, o projeto atual do PNAE apresenta importantes eixos de atuação como o incentivo à aquisição dos produtos da agricultura familiar, fomentando o desenvolvimento local e regional. Também é o único programa com 
atendimento universalizado, ou seja, abrange todos os estudantes matriculados na educação básica das escolas públicas, federais, comunitárias, confessionais e filantrópicas do país (BRASIL, 2020).

Essas e outras ações do PNAE fazem com que a experiência brasileira com alimentação escolar seja reconhecida mundialmente como um caso de sucesso (FAO, 2020). Neste sentido, Bittencourt (2007, p. 57) destaca que "na atualidade o Programa é um fator de qualidade da escola pública brasileira". A autora ainda afirma que a existência de programas similares em países desenvolvidos confirma a sua importância, pois representam instrumentos para enfrentar questões de saúde pública e uma opção educacional que qualifica a formação de seus cidadãos.

Conforme já mencionado, o PNAE é um programa suplementar do governo federal cuja operacionalização ocorre em regime de colaboração entre os entes federados, ou seja, cada membro possui responsabilidades e competências próprias para a sua efetivação.

Desta forma, o governo federal, por meio do FNDE, é responsável por definir as normas do programa, ou seja, elaboração da legislação, resoluções, instruções normativas e demais documentos que regem as ações do programa. Também atua no financiamento da política por meio de repasses de recursos financeiros aos entes federados. Já as entidades executoras são responsáveis pela complementação dos recursos financeiros, além de disponibilizar recursos humanos, materiais, estrutura física e proporcionar as condições necessárias para que o PNAE seja executado em conformidade com o que determina a legislação federal do programa.

Nos dias atuais, o processo de funcionamento do PNAE segue o seguinte fluxo: o FNDE, autarquia do governo federal, realiza repasse de recursos financeiros aos estados, municípios e escolas federais, com base no censo escolar do ano anterior de atendimento. Os valores financeiros, de caráter suplementar, são efetuados em 10 parcelas mensais (de fevereiro a novembro) para cobertura dos 200 dias letivos, de acordo com o número de estudantes matriculados em cada rede de ensino (BRASIL, 2020).

O valor repassado por dia letivo para cada aluno é definido conforme a modalidade de ensino, a saber: Creches: $\mathrm{R} \$ 1,07$; Pré-escola: $\mathrm{R} \$ 0,53$; Escolas indígenas e quilombolas: $\mathrm{R} \$ 0,64$; Ensino fundamental e médio: $\mathrm{R} \$ 0,36$; Educação de jovens e adultos: $\mathbf{R} \$ 0,32$; Ensino integral: $\mathbf{R} \$ 1,07$; Programa de Fomento às Escolas de Ensino Médio em Tempo Integral: R \$2,00; e Alunos que frequentam o Atendimento Educacional Especializado no contraturno: R\$ 0,53. É importante ressaltar que a aplicação desses recursos é fiscalizada e acompanhada pelo Tribunal de Contas da União (TCU), Ministério Público, Controladoria Geral da União (CGU), pelo próprio FNDE e diretamente por representantes da sociedade que 
integram o Conselho de Alimentação Escolar (CAE) que deve ser instituído em cada município, conforme recomenda a legislação do programa (BRASIL, 2020). Atualmente os principais dispositivos regulamentadores e normatizadores do PNAE são a Lei Federal no 11.947 de 16 de junho de 2009 e a Resolução $\mathrm{CD} / \mathrm{FNDE} \mathrm{n}^{\circ} 26$ de 17 de junho de 2013. A promulgação dessa legislação trouxe importantes avanços para o programa, tais como: a universalização do atendimento para os alunos matriculados na rede pública de educação básica; obrigatoriedade de aquisição dos produtos oriundos da agricultura familiar, incentivando o desenvolvimento local; ampliação dos eixos de atuação do programa, introduzindo a educação alimentar e nutricional no ambiente escolar; e fortalecimento do controle social, com a da participação da comunidade no Conselho de Alimentação Escolar (BRASIL 2009; 2013).

Além disso, também foram estabelecidos alguns critérios técnicos operacionais como a obrigatoriedade de um profissional nutricionista que responda tecnicamente pelo programa em âmbito local e a criação dos Centros Colaboradores em Alimentação e Nutrição do Escolar (CECANEs), por meio de parcerias entre as Instituições de Ensino Superior (IFEs) e o FNDE. Essas ações refletem uma importante ampliação e fortalecimento do PNAE, assegurando o direito à alimentação saudável e adequada nas escolas (BRASIL, 2015).

Embora seja evidente a evolução do PNAE desde sua concepção inicial, ainda existem desafios que precisam ser superados pelas entidades executoras na implementação do programa nas divergentes realidades dos 5.570 municípios brasileiros. Neste sentido, encontramos respaldo teórico em Arretche (2001, p. 51) ao afirmar que "a diversidade de contextos de implementação pode fazer que uma mesma regulamentação produza impactos inteiramente diversos em diferentes unidades da federação".

Diante disso, reafirmamos o propósito deste estudo que analisou a implementação do PNAE em municípios do norte gaúcho, identificando os desafios e potencialidades da gestão municipal na execução da política.

\section{MÉTODOS}

Para compreender o processo de implementação do PNAE em âmbito municipal optou-se por estudar a experiência de dois municípios situados na região norte do estado do Rio Grande do Sul (RS). 
Para fins de pesquisa e para preservar a identificação dos municípios, eles foram denominados ficticiamente de Município Mar e Município Rio. O critério utilizado para a seleção de ambos os municípios foi a localização, pois eram municípios que, na ocasião do estudo, se localizavam próximos à pesquisadora o que facilitou o deslocamento.

No quadro abaixo estão demonstradas, resumidamente, algumas características dos municípios investigados.

\section{Quadro 01 - Resumo das características dos municípios investigados na pesquisa.}

\begin{tabular}{|c|c|c|}
\hline Dados & Município Rio & Município Mar \\
\hline Habitantes (IBGE, 2019) & 2.693 & 105.059 \\
\hline IDH (IBGE, 2019) & 0,791 & 0,776 \\
\hline Índice de Gini (DATASUS, 2010) & 0,6236 & 0,4869 \\
\hline PIB per capita (IBGE, 2019) & $\mathrm{R} \$ 26.388,40$ & $\mathrm{R} \$ 43.052,17$ \\
\hline Matrículas Ed. Básica (MEC/INEP, 2018) & $\begin{array}{c}304 \\
\text { (84 rede pública municipal) }\end{array}$ & $\begin{array}{c}19.906 \\
\text { (6.336 rede pública municipal) }\end{array}$ \\
\hline $\mathrm{N}^{0}$ de escolas municipais & 02 & $\begin{array}{l}20 \text { (incluindo anexos e instituições } \\
\text { sociais) }\end{array}$ \\
\hline Recurso financeiro FNDE - PNAE (2018) & $\begin{array}{c}\mathrm{R} \$ 11.538,00 \\
\text { (R\$ 0,68/dia/aluno) }\end{array}$ & $\begin{array}{c}\mathrm{R} \$ 898.296,00 \\
\text { (R\$ 0,71/dia/aluno) }\end{array}$ \\
\hline Contrapartida financeira municipal (2018) & $\begin{array}{c}\mathrm{R} \$ 13.652,83 \\
\text { (R\$ 0,81/dia/aluno) }\end{array}$ & $\begin{array}{c}\mathrm{R} \$ 891.158,98 \\
\text { (R\$ 0,70/dia/aluno) }\end{array}$ \\
\hline $\begin{array}{c}N^{0} \text { de nutricionistas atuantes no PNAE } \\
\text { em âmbito municipal }\end{array}$ & $\begin{array}{c}01 \\
\text { (12 horas semanais) }\end{array}$ & $\begin{array}{c}04 \\
\text { (40 horas semanais cada) }\end{array}$ \\
\hline
\end{tabular}

Fonte: O autor, 2019.

Foram empregadas as seguintes técnicas de pesquisa para coleta e análise dos dados: análise documental e entrevistas semiestruturadas, conforme quadro 02 .

\section{Quadro 02 - Técnicas empregadas no estudo e sua aplicação.}

\begin{tabular}{|c|c|}
\hline Técnica & Aplicação \\
\hline Análise documental & $\begin{array}{r}\text { Legislação que regulamenta o PNAE, documentos oficiais de domínio público e demais } \\
\text { disponibilizados pela gestão municipal. }\end{array}$ \\
\hline Entrevista semiestruturada & $\begin{array}{r}\text { Agentes implementadores da política em âmbito municipal, com vínculo profissional com o } \\
\text { PNAE (secretários de educação, nutricionistas, membros do CAE). }\end{array}$ \\
\hline
\end{tabular}

Fonte: O autor, 2019. 
A técnica de análise documental foi desenvolvida conforme orienta Cellard (2012). Segundo o autor, sob o ponto de vista metodológico a análise documental apresenta vantagens significativas e a define desse modo:

[...] trata-se de um método de coleta de dados que elimina, ao menos em parte, a eventualidade de qualquer influência -a ser exercida pela presença ou intervenção do pesquisador -do conjunto das interações, acontecimentos ou comportamentos pesquisados, anulando a possibilidade de reação do sujeito à operação de medida. (CELLARD, 2012, p. 295).

Desta forma, foram analisados os documentos oficiais como a legislação federal que rege o PNAE (Lei Federal n ${ }^{\circ} 11.947 / 2009$ e Resolução CD/FNDE n ${ }^{\circ}$ 26 de 2013), bem como documentos disponibilizados pelas Secretarias Municipais de Educação e as informações encontradas nos sites oficiais das prefeituras dos municípios investigados, compreendendo o período de 2013 a 2018.

Também era necessário conhecer e compreender a atuação dos profissionais na implementação do PNAE em âmbito municipal. Diante disso, optou-se pela técnica de entrevista semiestrutura que de acordo com Flick (2009) consiste em um roteiro onde são preparadas várias perguntas que cobrem o escopo pretendido da entrevista, cujo objetivo é obter as visões individuais dos entrevistados sobre um tema.

As entrevistas semiestruturadas foram direcionadas às pessoas que possuíam vinculo profissional com o PNAE nos municípios selecionados para o estudo. Assim, no Município Mar participaram da entrevista: três nutricionistas, a secretária adjunta de educação e um membro do CAE (representante do segmento executivo). Já, no Município Rio, foram entrevistados os seguintes profissionais: a nutricionista, a secretária de educação e um conselheiro do CAE, também representante do segmento executivo.

Posteriormente, foi realizado o cruzamento dos dados e a análise conjunta das informações.

\section{RESULTADOS}

Para nortear a análise dos dados e auxiliar na organização da pesquisa, foram criadas as seguintes categorias analíticas: operacionalização do PNAE e agentes implementadores da política. É importante esclarecer que essas categorias foram pensadas com base nos critérios de análise de implementação de políticas públicas e na estrutura da própria política nacional de alimentação escolar. 


\section{OPERACIONALIZAÇÃO DO PNAE}

O processo de operacionalização do PNAE em ambos os municípios investigados ocorre em regime de colaboração com o governo federal. Um dos principais aspectos desse processo é a disponibilidade de recursos financeiros para aquisição dos alimentos que serão utilizados na alimentação escolar. Assim sendo, o governo federal repassa de forma suplementar recursos financeiros às entidades executoras e estas, por sua vez, são responsáveis pela complementação desses recursos.

No quadro abaixo, são apresentadas informações referentes aos recursos financeiros repassados pelo governo federal aos municípios Rio e Mar e a contrapartida das entidades executoras para a execução do PNAE, no período de 2013 a 2018.

\section{Quadro 03 - Recursos financeiros investidos no PNAE pelo governo federal e pelos municípios investigados no período de 2013 a 2018.}

\begin{tabular}{|c|c|c|c|c|c|c|}
\hline & \multicolumn{3}{|c|}{ Município Rio } & \multicolumn{3}{c|}{ Município Mar } \\
\cline { 2 - 7 } Ano & $\begin{array}{c}\mathbf{N}^{0} \text { de alunos } \\
\text { atendidos pelo } \\
\text { PNAE }^{3}\end{array}$ & $\begin{array}{c}\text { Recursos } \\
\text { financeiros } \\
\text { repassados } \\
\text { pelo FNDE } \\
(\mathbf{R} \$)^{4}\end{array}$ & $\begin{array}{c}\text { Contrapartida } \\
\text { municipal } \\
(\mathbf{R} \$)^{5}\end{array}$ & $\begin{array}{c}\mathbf{N}^{\circ} \text { de alunos } \\
\text { atendidos pelo } \\
\text { PNAE }\end{array}$ & $\begin{array}{c}\text { Recursos } \\
\text { financeiros } \\
\text { repassados } \\
\text { pelo FNDE } \\
(\mathbf{R} \$)\end{array}$ & $\begin{array}{c}\text { Contrapartida } \\
\text { municipal (R\$) }\end{array}$ \\
\hline 2013 & 122 & $23.700,00$ & $26.214,36$ & 6.092 & $850.708,00$ & $658.195,83$ \\
\hline 2014 & 113 & $21.200,00$ & $33.572,46$ & 6.222 & $723.040,00$ & $1.175 .400,85$ \\
\hline 2015 & 114 & $19.400,00$ & $13.500,17$ & 6.187 & $921.708,00$ & $433.036,29$ \\
\hline 2016 & 100 & $13.080,00$ & $20.309,05$ & 6.234 & $904.600,00$ & $975.717,31$ \\
\hline 2017 & 93 & $13.002,00$ & $11.548,21$ & 6.300 & $965.836,00$ & $918.965,89$ \\
\hline 2018 & 84 & $11.538,00$ & $13.652,83$ & 6.336 & $898.296,00$ & $891.158,98$ \\
\hline
\end{tabular}

Fonte: O autor, 2019.

3 As informações foram obtidas no site oficial do MEC/INEP conforme os indicadores dos municípios Rio e Mar. Disponível em: < https://inepdata.inep.gov.br/analytics/saw.dll?Dashboard\&PortalPath= $\% 2$ Fshare $\mathrm{d} \% 2 \mathrm{FIntegra} \% \mathrm{C} 3 \% \mathrm{~A} 7 \% \mathrm{C} 3 \% \mathrm{~A} 3 \mathrm{O} \% 20$ - $\% 20$ Consulta $\% 20 \mathrm{Matr} \% \mathrm{C} 3 \%$ ADcula $\% 2 \mathrm{~F} \_$portal $\% 2 \mathrm{FC}$ onsulta $\% 20$ Matr\%C3\%ADcula\&Page=Consolidado\%20por\%20UF>. Acesso em 21 maio e 05 de jun. de 2019.

4 Os dados foram obtidos no site oficial do FNDE, na página destinada ao PNAE para consulta às liberações dos recursos financeiros, de acordo com os indicadores dos municípios Rio e Mar. Disponível em: <https://www.fnde.gov.br/sigefweb/index.php/liberacoes>. Acesso em 21 de maio e 05 de jun. de 2019.

5 As informações foram obtidas junto às Secretarias Municipais de Educação dos municípios investigados. 
Com base no quadro acima é possível verificar que, na maioria dos anos, a contrapartida financeira do Município Rio foi semelhante ou superior aos recursos financeiros repassados pelo FNDE para execução do PNAE. Já o Município Mar, com exceção dos anos 2014 e 2016, disponibilizou menos recursos financeiros ao programa quando comparado com o valor repassado pelo governo federal. Isso se deve, em parte, pelo quantitativo significativo de estudantes atendidos na rede pública municipal de educação básica do Município Mar, o que exige da entidade executora uma provisão maior de recursos financeiros para atender a essa clientela.

Além disso, nos dias atuais não existe um percentual mínimo que a entidade executora deve investir em recursos financeiros no PNAE, cada unidade direciona os recursos conforme sua disponibilidade orçamentária.

A partir da liberação dos recursos financeiros, tanto pelo governo federal quanto pelas entidades executoras, é realizado o planejamento para a aquisição dos gêneros alimentícios para a merenda escolar. Atualmente em ambos os municípios esse procedimento é realizado por meio de licitações (modalidade pregão presencial, do tipo menor preço) e chamada pública, conforme orienta a legislação brasileira. O processo licitatório é destinado para a compra de alimentos de estabelecimentos comerciais como supermercados, fruteiras, etc. Já a chamada pública se restringe à aquisição de alimentos da agricultura familiar, que pode ser de produtores rurais individuais ou de associações e/ou cooperativas destes.

Embora esse processo seja semelhante em ambos os municípios, verificou-se que no Município Mar a aquisição dos alimentos é mais rigorosa, além de cumprir com os procedimentos convencionais para habilitação dos fornecedores, também são exigidas amostras de cada produto que compõe os editais de licitação e chamada pública. Isso se deve pela equipe que atua no PNAE deste município que é composta por 04 nutricionistas com carga horária de 40 horas semanais cada, enquanto o município Rio possui uma nutricionista que dedica 12 horas semanais ao programa.

Outro fator que chama a atenção quanto à operacionalização do programa nos municípios estudados é o percentual de aquisição dos produtos oriundos da agricultura familiar. A Lei Federal no 11.947 de 2009 recomenda em seu art. 14 que, pelo menos, 30\% dos recursos financeiros repassados pelo FNDE, no âmbito do PNAE, devem ser investidos na aquisição de produtos da agricultura familiar. De acordo com informações dos agentes implementadores da política, no município Rio 70\% desse recurso é utilizado na aquisição desses produtos, já o município Mar direciona 100\% do recurso para esta finalidade. 
Atualmente os municípios adquirem, via chamada pública, diversos alimentos da agricultura familiar para compor o cardápio da alimentação escolar. Entre eles, podemos citar produtos de panificação (pão, bolachas, cuca, grostoli, pastel assado, massa para pizza, anholigne, etc.), hortifrutigranjeiros (frutas, verduras, legumes, ovos, etc.), leguminosas (feijão), carnes, leite e derivados (iogurte), grãos e cereais (arroz, farinha de milho), entre outros. Segundo relato dos gestores, os produtos são fresquinhos e de boa qualidade, além disso, há uma preocupação com o uso de agrotóxicos e com as práticas sustentáveis de produção para ofertar uma alimentação mais saudável no ambiente escolar, o que qualifica a alimentação servida nas escolas. Isso pode ser evidenciado nos relatos abaixo dos participantes do estudo:

“[...] a gente teve uma reunião com a agricultura familiar e eles frisaram que muitos estão deixando de usar agrotóxicos. Então, mais uma vantagem para nós fornecer da agricultura familiar, porque eles estão tentando sair um pouco desses agrotóxicos. Muitos acabam tendo uma alimentação totalmente industrializada, mas pelo menos na escola um pouquinho mais sem agrotóxico, um pouquinho mais saudável" (ATOR 05, 29 nov. 2018).

“[...] tem a parte dos alimentos, da compra da agricultura familiar, onde o recurso acaba ficando aqui para nossa região, né. O agricultor gerando emprego e a renda ficando aqui na nossa região" (ATOR 04, 29 nov. 2018).

Esses dados demonstram a relevância do programa para o desenvolvimento econômico local e regional. A política de incentivo à aquisição dos alimentos da agricultura familiar, via PNAE, fortaleceu a produção agrícola dos municípios com a criação de agroindústrias familiares. Além disso, com base na renda dos alimentos que serão fornecidos à alimentação escolar, os agricultores planejam sua produção e conseguem investir os recursos em suas propriedades rurais.

Em relação aos obstáculos enfrentados pelas entidades executoras na implementação do PNAE, as maiores dificuldades apontadas pelos gestores da política em âmbito municipal foram: burocracia dos processos, resistências da equipe e disponibilidade dos recursos financeiros.

Segundo os gestores a burocracia dos processos é um dos principais fatores dificultadores na execução do programa, devido à complexidade dos procedimentos e aos imprevistos que podem surgir durante os processos de licitação e chamada pública (impugnação de editais, recursos etc.), interferindo na disponibilidade dos produtos utilizados na alimentação escolar, conforme relato abaixo dos atores 02 e 05 . Além disso, as exigências da legislação em relação à documentação, a pesquisas de preços, à prestação de contas, entre outros, 
demandam muito tempo e trabalho dos agentes públicos. Essa questão também pode estar relacionada à falta constante de capacitações da equipe que atua no PNAE e que pode refletir na operacionalização do programa.

"O que dificulta, talvez, uma das coisas que poderia se colocar é a burocracia em si, porque tu tens que fazer os levantamentos de preços e tal, mas é uma coisa que se deve fazer né, mas é uma coisa bem burocrática, trabalhosa, talvez se fosse um pouquinho mais simples. A prestação de contas não é fácil, é bem difícil de fazer [...]” (ATOR 02, 10 dez. 2018).

\begin{abstract}
"Para atingir todas as demandas que a lei exige, tem que seguir todos os parâmetros, porém, demora muito tempo até chegar o produto na escola. Então, a gente já tem que estar encaminhando (a licitação e a chamada pública) agora em novembro, para que em fevereiro os produtos estejam nas escolas e ainda assim não é garantia, porque há fornecedores que entram com recurso no decorrer do processo, então acaba interferindo ali também. E antes a gente não consegue mandar porque temos que esperar o recurso (financeiro) da prefeitura, quanto que vai ser disponibilizado, tem que esperar o resultado do censo escolar, quanto o FNDE vai disponibilizar de recurso (financeiro). Antes disso fica dificultoso a gente começar a realizar a compra, porque não temos recurso (financeiro), e a partir disso podem acontecer imprevistos no meio do caminho" (ATOR 05, 29 nov. 2018).
\end{abstract}

A disponibilidade de recursos financeiros é outro fator que interfere diretamente na execução da política, pois para dar início aos processos de aquisição dos gêneros alimentícios é preciso saber quais serão os valores destinados pelo FNDE e pela entidade executora para o PNAE e, nem sempre, essas informações estão disponíveis com a antecedência necessária. Aliado a isso, geralmente, as últimas parcelas financeiras do FNDE são creditadas às entidades executoras no final do mês de dezembro inviabilizando a utilização desse recurso no mesmo ano letivo. Diante disso, o saldo pode ser reprogramado para o início do próximo ano ou utilizado para a aquisição de produtos não perecíveis que são mantidos em estoque para uso no início do período letivo.

Além disso, os gestores consideram insuficientes os recursos financeiros repassados pelo FNDE às entidades executoras, pois a administração municipal precisa dispor de uma contrapartida significativa para atender as demandas do programa. Neste ponto, percebe-se que a maioria dos gestores ainda não compreendeu o caráter suplementar da política e que é dever da entidade executora arcar com o suporte financeiro para o adequado funcionamento do PNAE.

Com relação à equipe de trabalho, os gestores relatam que ainda há muitas resistências, principalmente no ambiente escolar, no que diz respeito à execução dos cardápios estabelecidos pelas nutricionistas. Essa prática interfere em todo o planejamento da alimentação escolar, pois os produtos são adquiridos conforme 
os cardápios elaborados e seu descumprimento implica em uma reorganização dos produtos e quantitativos disponíveis para atender as escolas durante todo o período letivo. Além disso, as alterações nos cardápios, sem o conhecimento prévio do profissional nutricionista, podem comprometer o equilíbrio nutricional da alimentação ofertada nas escolas.

Já em relação aos fatores que colaboram para a implementação do PNAE em âmbito municipal, os agentes implementadores destacam o repasse de recursos financeiros pelo governo federal e o trabalho da equipe que atua no programa.

Embora os recursos financeiros disponibilizados pelo governo federal sejam insuficientes para atender as demandas do PNAE, a ausência desses valores comprometeria a execução da política nos municípios investigados, pois as entidades executoras não teriam condições de aportar o montante financeiro necessário para oferecer a alimentação escolar nos moldes recomendados pela legislação do programa, conforme pode ser evidenciado no relato abaixo do ator 05 que participou da pesquisa. Ou seja, a ausência dos repasses financeiros pelo governo federal impactaria diretamente na execução da política em âmbito municipal ou até na extinção desta, como é o caso da rede pública estadual de educação básica que conta apenas com os recursos disponibilizados pelo governo federal para o funcionamento do PNAE nas escolas estaduais.

“[...] só o município não teria recursos suficientes, porque o número de alunos é muito alto e a maioria dos nossos alunos, não digo todos, mas grande parte são carentes e realmente fazem suas refeições principais na escola. Então, se não tivesse esse recurso, talvez a gente não poderia colocar turnos integrais e ofertar tantas refeições assim só com o recurso do município, o município não teria como sustentar o programa" (ATOR 05, 29 nov. 2018).

O trabalho desenvolvido pela equipe que atua no PNAE em âmbito municipal foi outro fator citado como positivo. Os profissionais preocupam-se em seguir o que determina a legislação do programa e desenvolvem suas ações de acordo com esta. Também foi destacada a atuação dos profissionais nutricionistas no PNAE, pois o conhecimento técnico e o trabalho realizado qualificam a alimentação escolar.

Ainda, nos municípios investigados, os gestores consideram a política nacional de alimentação escolar benéfica, pois oportuniza o acesso à alimentação saudável a um número significativo de estudantes, além de promover o desenvolvimento socioeconômico local, por meio do incentivo à aquisição dos produtos da agricultura familiar. Contudo, apontam alguns aspectos da política que poderiam ser melhorados, tanto em âmbito local quanto nacional, para aprimorar as ações do PNAE, como: melhorar os valores financeiros (valor/ aluno) e adiantar o repasse das últimas parcelas do governo federal para que as 
entidades executoras possam utilizar os recursos no mesmo ano letivo; investir em capacitações da equipe que atua no programa e na sua articulação; melhorar o quadro técnico com a contratação de mais profissionais nutricionistas ou técnicos em nutrição para atuarem no PNAE; além de disponibilizar um sistema integrado junto às escolas com a possibilidade de acompanhar o controle de estoque e a execução dos cardápios, auxiliando no gerenciamento mais eficaz da alimentação escolar.

\section{AGENTES IMPLEMENTADORES DA POLÍTICA}

A implementação da política depende do trabalho conjunto de vários atores, que atuam ou participam das diferentes fases do programa, conforme demonstrado no quadro abaixo:

\section{Quadro 04 - Atores do PNAE e suas respectivas fases da política.}

\begin{tabular}{|c|c|c|c|}
\hline \multicolumn{2}{|c|}{ Fases } & Âmbito Nacional & Âmbito Municipal \\
\hline \multicolumn{2}{|c|}{ Agentes formuladores } & $\begin{array}{l}\text { Governo Federal por meio } \\
\text { do FNDE }\end{array}$ & \\
\hline \multirow{2}{*}{$\begin{array}{c}\text { Agentes } \\
\text { implementadores }\end{array}$} & Equipe principal & & $\begin{array}{l}\text { Entidade Executora (Prefeituras Municipais por meio } \\
\text { das Secretarias Municipais de Educação e/ou do } \\
\text { Setor de Alimentação Escolar) } \\
\text { Nutricionistas } \\
\text { CAE } \\
\text { Membros da equipe diretiva das escolas } \\
\text { Merendeiras e auxiliares }\end{array}$ \\
\hline & Equipe de suporte & & $\begin{array}{l}\text { Membros da SMED (secretários(as), professores e } \\
\text { coordenadores do Setor de Alimentação Escolar) } \\
\text { Setor de compras e licitações } \\
\text { Setor de contabilidade } \\
\text { Tesouraria e/ou Secretaria Municipal da Fazenda } \\
\text { Auxiliares administrativos da gestão municipal } \\
\text { Emater }\end{array}$ \\
\hline Público-alvo & & & $\begin{array}{l}\text { Alunos matriculados na rede pública municipal de } \\
\text { educação básica }\end{array}$ \\
\hline
\end{tabular}

Fonte: O autor, 2019.

É importante destacar que em ambos os municípios investigados o profissional nutricionista exerce papel fundamental na implementação do PNAE. Geralmente, eles estão presentes em todas as etapas de execução do programa, desde o processo de aquisição dos alimentos, participando da confecção dos editais de licitação e chamamento público, acompanhando as diversas etapas da política até a alimentação atingir seu público final, ou seja, os alunos das escolas 
públicas municipais. Muitas vezes, o nutricionista acaba gerindo o programa, tornando-se um dos principais agentes implementadores da política em âmbito municipal.

Entretanto, ainda se verifica a subvalorização desse profissional no âmbito do PNAE, pois as entidades executoras não respeitam os parâmetros mínimos estabelecidos pela Resolução CFN no 465/2010 para a atuação do nutricionista no programa. Por exemplo, a nutricionista do Município Rio atua 12 horas semanais no PNAE, contudo de acordo com as recomendações da resolução acima citada, ela deveria dedicar uma carga horaria mínima de 30 horas semanais ao programa. Resultados semelhantes também foram verificados no estudo realizado por Nicoletti (2017), sobre a implementação do PNAE no município de Natal/RN. A autora verificou que o número de nutricionistas e a carga horária dedicada ao PNAE na entidade executora eram insuficientes para atender as diretrizes da Resolução CFN no 465/2010.

Também colaboram na implementação do PNAE outros profissionais da administração municipal como: membros da secretaria municipal de educação (secretários(as) de educação, professores e/ou coordenadores do setor de alimentação escolar). Além disso, podemos destacar o trabalho desenvolvido por outros agentes e setores públicos como:

1. Setor de compras e licitações: é responsável pelos processos de aquisição dos gêneros alimentícios (elaboração e execução dos editais de licitações e chamadas públicas, chamamento e habilitação de fornecedores, orçamentos e pesquisas de preços).

2. Setor de contabilidade: colabora no controle e empenho dos recursos financeiros, autoriza o pagamento das notas fiscais aos fornecedores, atua na emissão de relatórios para a prestação de contas do programa.

3. Secretaria municipal da fazenda ou tesouraria: atua na execução dos pagamentos das notas fiscais para os fornecedores e auxilia no controle dos recursos financeiros.

4. Administrativo: auxilia na organização da documentação e na prestação anual de contas do PNAE ao FNDE.

Ainda, auxiliam no funcionamento do PNAE os agentes que atuam diretamente nas escolas como: a equipe diretiva, as cozinheiras, merendeiras, auxiliares de cozinha e limpeza, colaborando em diversas etapas do processo que vão desde o recebimento e produção dos alimentos, distribuição e acompanhamento das refeições, até o preenchimento de planilhas e relatórios de controle. 
Cabe destacar a parceira da Emater na execução do PNAE em âmbito municipal. A entidade colabora com o cadastramento e diálogo com os produtores rurais para o fornecimento dos insumos à alimentação escolar. Vale lembrar que esse também é um dos eixos de atuação do programa, contribuindo para o desenvolvimento econômico e sustentável da região.

Por fim, evidenciamos a relevância do trabalho realizado pelo Conselho de Alimentação Escolar (CAE) no PNAE. O CAE corresponde a um órgão de controle e participação social e representa um importante agente fiscalizador dos recursos financeiros recebidos e aplicados no programa. Geralmente, os conselheiros reúnem-se periodicamente e realizam visitas às escolas para averiguar in loco as ações referentes ao programa. Também são responsáveis por emitirem relatórios e os pareceres sobre a prestação de contas do PNAE.

Um dos aspectos que chamou a atenção durante o desenvolvimento da pesquisa foi a deficiência relacionada à capacitação da equipe que atua no PNAE. Em ambos os municípios investigados, os agentes implementadores participaram esporadicamente de cursos de formação e/ou capacitação relacionados ao programa. É importante destacar que a ausência frequente de capacitações da equipe pode interferir na sua atuação e até mesmo no funcionamento do programa, pois a falta de informações pode afetar no desempeno adequado das ações relacionadas ao PNAE. Ainda, cabe ressaltar que a legislação do programa estabelece que é responsabilidade da entidade executora em parceria com o FNDE realizar a capacitação dos recursos humanos envolvidos na execução do PNAE e no controle social (art. 17, inciso IV, da Lei Federal 11.947 de 2009 e art. 60 da Resolução CD/FNDE nº 23 de 2013).

É possível constatar que a operacionalização do PNAE é um trabalho complexo e que depende da atuação de vários agentes implementadores da política para que os objetivos e diretrizes do programa sejam alcançados. Embora os agentes exerçam funções e atribuições distintas, é o trabalho conjunto deles que permite que a alimentação escolar atinja o seu público-alvo e que seus resultados estejam em conformidade com os princípios estabelecidos pela política em âmbito nacional.

\section{CONSIDERAÇÕES FINAIS}

Ao retomarmos os objetivos e embasamento teórico do estudo, podemos afirmar que a implementação do PNAE, em âmbito municipal, depende de três fatores básicos: recursos financeiros, agentes da política e sistema normativo que rege as ações do PNAE, conforme puderam ser evidenciados nesta pesquisa. 
A análise dos resultados demonstrou que o processo de implementação do PNAE é semelhante nos municípios investigados. A operacionalização do programa ocorre em regime de colaboração com o governo federal e os agentes implementadores possuem cargos e funções similares em ambos os municípios estudados, contudo existem características locais que impactam na implementação do programa e definem algumas ações em relação à execução da política em âmbito local.

Com base nos dados apresentados no estudo foi possível verificar que existem diferenças significativas entre as características dos municípios estudados que refletem na execução do PNAE.

O Município Rio representa uma cidade de pequeno porte, atende um número reduzido de alunos e escolas e, consequentemente, possui um quadro menor de profissionais que atuam no programa. Contudo, a entidade executora consegue disponibilizar mais recursos financeiros ao programa e os gestores conseguem acompanhar a execução da política no ambiente escolar. Já o Município Mar possui um número considerável de alunos e escolas, o que dificulta em parte o funcionamento do programa, pois a entidade executora precisa prover valores significativos para o financiamento do PNAE e os gestores não conseguem monitorar o programa rotineiramente junto às escolas.

Esse cenário demonstra que a operacionalização do PNAE em municípios de pequeno porte é mais eficaz, pois as características locais permitiram uma melhor implementação do programa, refletindo no impacto da política em relação ao público-alvo.

Contudo, podemos afirmar que a política é exitosa em ambos os municípios investigados, pois ela atende os princípios propostos e seus benefícios ultrapassam os muros da escola, impactando positivamente a sociedade local.

É importante ressaltar que ainda existem fragilidades que precisam ser trabalhadas para minimizar as dificuldades das entidades executoras na implementação do PNAE. Diante disso, destacamos a importância de novas pesquisas com viés para a análise e avaliação da política nacional de alimentação escolar, em seus diversos eixos de atuação, com o intuito de aprimorar as ações do PNAE e potencializar sua efetivação nas diferentes regiões do país. 


\section{REFERÊNCIAS}

ANTONIOLLI, Elitana. Programa Nacional de Alimentação Escolar (PNAE): Uma Análise da Implementação em Municípios do Rio Grande do Sul (RS). 2019. 159f. Dissertação (Mestrado em Educação) - Programa de Pós-Graduação em Educação, Universidade Federal da Fronteira Sul, Chapecó, SC, 2019.

ARRETCHE, Marta. Uma contribuição para fazermos avaliações menos ingênuas. In: BARREIRA, Maria Cecília; CARVALHO, Maria do Carmo (Orgs). Tendências e perspectivas na avalição de políticas e programas sociais. São Paulo: IEE/PUC-SP, p. 43-56, 2001.

BALL, S.J.; BOWE, R. Subject departments and the "implementation" of National Curriculum policy: an overview of the issues. Journal of Curriculum Studies, London, v. 24, n. 2, p. 97-115, 1992. Disponível em: < file:///C:/Users/ User/Downloads/Subjectdepartments.pdf>. Acesso em: 03 jun. 2021.

BITTENCOURT, Jaqueline Marcela Villafuerte. Uma Avaliação da Efetividade do Programa de Alimentação Escolar no Município de Guaíba. 2007. 164f. Dissertação (Mestrado em Educação) -Faculdade de Educação, Programa de Pós-Graduação em Educação, Universidade Federal do Rio Grande do Sul, Porto Alegre, RS, 2007.

BOBBIO, Norberto. A era dos direitos. Rio de Janeiro: Campus, 1992.

BRASIL. Constituição da República Federativa do Brasil de 1988. Disponível em: <http://www.planalto.gov.br/ccivil_03/constituicao/ constituicaocompilado.htm>. Acesso em: 07 mar. 2020.

Lei $\mathbf{n}^{0} \mathbf{9 . 3 9 4}$ de 20 de dezembro de 1996. Estabelece as diretrizes e bases da educação nacional. Disponível em: <http://www.planalto.gov.br/ Ccivil_03/leis/L9394.htm>. Acesso em: 08 mar. 2020.

Lei $\mathrm{n}^{\circ} 11.947$ de 16 de junho de 2009. Dispõe sobre o atendimento da alimentação escolar e do Programa Dinheiro Direto na Escola aos alunos da educação básica. Disponível em: < http://www.planalto.gov.br/ccivil_03/_ ato2007-2010/2009/lei/111947.htm>. Acesso em: 31 mar. 2020. 
. Resolução CD/FNDE no 26, de 17 de junho de 2013. Dispõe sobre o atendimento da alimentação escolar aos alunos da educação básica no âmbito do Programa Nacional de Alimentação Escolar - PNAE. Disponível em: <http:// www.fnde.gov.br/acesso-a-informacao/institucional/legislacao/item/4620resolu $\%$ C3\%A7\%C3\%A3o-cd-fnde-n \%C2\%BA-26,-de-17-de-junho-de-2013>. Acesso em: 01 abr. 2020.

- Ministério da Educação. Fundo Nacional de Desenvolvimento da Educação (FNDE). Cartilha Nacional da Alimentação Escolar. Brasília, DF, $2^{\mathrm{a}}$ ed., 2015, $88 \mathrm{p}$.

- Ministério da Educação. Fundo Nacional de Desenvolvimento da Educação (FNDE). Programa Nacional de Alimentação Escolar. Disponível em: http://www.fnde.gov.br/programas/alimentacao-escolar. Acesso em: 03 mar. 2020.

- Ministério da Educação. Instituto Nacional de Estudos e Pesquisas Educacionais Anísio Teixeira (INEP). Consulta matrícula. Disponível em: $<$ http://portal.inep.gov.br/web/guest/dados/consulta-matricula>. Acesso em: 03 abr. 2020.

. Resolução CFN no 465, de 23 de agosto de 2010. Dispõe sobre as atribuições do Nutricionista, estabelece parâmetros numéricos mínimos de referência no âmbito do Programa de Alimentação Escolar (PAE) e dá outras providências. Disponível em: <http://www.cfn.org.br/wp-content/uploads/ resolucoes/Res_465_2010.htm>. Acesso em: 23 abr. 2020.

CELLARD, André. Análise Documental. In: POUPART, Jean et al. A pesquisa qualitativa: enfoques epistemológicos e metodológicos. Petrópolis, RJ: Vozes, 3aed., p. 295-316, 2012.

DUDH, Declaração Universal dos Direitos Humanos. Declaração Universal dos Direitos Humanos. 1948. Disponível em: < https://nacoesunidas.org/wpcontent/uploads/2018/10/DUDH.pdf>. Acesso em: 15 mar. 2020.

FAO, Organização das Nações Unidas para a Alimentação e a Agricultura. Alimentación y nutrición escolar. Disponível em: <http://www.fao.org/ school-food/es/>. Acesso em: 29 mar. 2020. 
FLICK, Uwe. Desenho da pesquisa qualitativa. Porto Alegre: Bookman, 2009. $164 \mathrm{p}$.

- Introdução à metodologia de pesquisa: um guia para iniciantes. Porto Alegre, RS: Penso, 2013. 256 p.

FREY, Klaus. Políticas Públicas: um debate conceitual e reflexões referentes à prática da análise de políticas públicas no Brasil. Planejamento e Políticas Públicas, $n^{\circ}$ 21, p. 211-259, jun. 2000. Disponível em: <http://www.ipea.gov.br/ ppp/index.php/PPP/article/view/89/158>. Acesso em: 30 mar. 2020.

HOFLING, Eloisa de Mattos. Estado e Políticas (Públicas) Sociais. Cadernos Cedes, ano XXI, no 55, nov. 2001. Disponível em: <http://www.scielo.br/pdf/ ccedes/v21n55/5539.pdf>. Acesso em: 25 mar. 2020.

LIMA, Luciana Leite; D’ASCENZI, Luciano. Implementação de Políticas Públicas: perspectivas analíticas. Rev. Sociol. Polít., Curitiba, v. 21, n. 48, p. 101-110, dez. 2013. Disponível em: <http://www.scielo.br/pdf/rsocp/v21n48/ a06v21n48.pdf >. Acesso em: 10 abr. 2020.

MAINARDES, Jefferson. Abordagem do ciclo de políticas: uma contribuição para a análise de políticas educacionais. Educação \& Sociedade, Campinas, v. 27, n. 94, p. 47-69, jan. /abr. 2006. Disponível em: <https://www.scielo.br/j/ es/a/NGFTXWNtTvxYtCQHCJFyhsJ/?lang=pt\&format=pdf $>$. Acesso em: 03 jun. 2021.

NICOLET'TI, Milena Paiva. Análise da implementação do Programa Nacional de Alimentação Escolar - PNAE no Município de Natal/RN a partir dos arranjos institucionais locais. 2017. 138f. Dissertação (Mestrado) - Centro de Ciências Humanas, Letras e Artes, Programa de Pós-Graduação em Estudos Urbanos e Regionais, Universidade Federal do Rio Grande do Norte, Natal, RN, 2017.

PEREZ, José Roberto Rus. Por que pesquisar implementação de políticas educacionais atualmente? Educ. Soc., Campinas, v. 31, n. 113, p. 1179-1193, out.dez. 2010. Disponível em: <http://www.scielo.br/pdf/es/v31n113/07.pdf>. Acesso em: 07 abr. 2020. 
SOUZA, Celina. Políticas Públicas: uma revisão da literatura. Sociologias, Porto Alegre, ano 8, no 16, p. 20-45, jul/dez 2006. Disponível em: < http://www.scielo. br/pdf/soc/n16/a03n16>. Acesso em: 29 mar. 2020.

\section{Elitana Antoniolli}

Mestra em Educação pela Universidade Federal da Fronteira Sul (UFFS), Campus Chapecó/ SC. Servidora pública, atua no cargo de nutricionista da UFFS - Campus Erechim/ RS. E-mail: elitanaa@hotmail.com

\section{Maria Silvia Cristofoli}

Doutora em Educação pela Universidade Federal do Rio Grande do Sul (UFRGS). Professora da Universidade Federal da Fronteira Sul (UFFS) Campus Erechim/ RS, possui experiência docente na educação superior em cursos de licenciatura e especialização, também atua como professora nos cursos de Mestrado em Educação e Mestrado Profissional em Educação da UFFS. E-mail: mscristofoli@uffs.edu.br 